\title{
Expression profile of microRNAs in fetal lung development of Sprague-Dawley rats
}

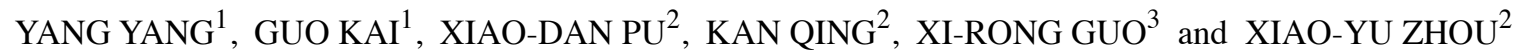 \\ ${ }^{1}$ Institute of Pediatrics, Nanjing Medical University, Nanjing 210029; ${ }^{2}$ Department of Neonates, Nanjing Children's \\ Hospital of Nanjing Medical University, Nanjing 210008; ${ }^{3}$ Department of Pediatrics, Nanjing Maternal \\ and Child Health Hospital of Nanjing Medical University, Nanjing 210004, P.R. China
}

Received October 9, 2011; Accepted November 14, 2011

DOI: $10.3892 / \mathrm{ijmm} .2011 .855$

\begin{abstract}
As well-known regulators of gene expression, microRNAs (miRNAs) play an important role not only in cell proliferation and differentiation, but also in tumorigenesis and organ development. Furthermore, it is estimated that miRNAs may be responsible for regulating the expression of nearly one-third of the human genome. Simultaneously, in the clinic, with advances in neonatal care, a larger number of premature infants are being saved, and thus diseases of lung development, including bronchopulmonary dysplasia (BPD) have become more and more common. However, only a few miRNA studies have studied their connection with diseases of lung development. In our study, we used a miRNA microarray including more than 1891 capture probes to profile the expression of miRNAs at three time points of rat lung development [embryonic (E) Day 16 (E16), E19, E21]. miRNAs found to have consistent fold-changes (fold-change $>2.0$ ) during all three time points were selected and validated by real-time PCR. As a result, 167 differentially expressed miRNAs were found during rat lung organogenesis, including 81 upregulated and 86 downregulated miRNAs. Seven miRNAs were selected and characterized by having a consistent $>2$-fold changes between all three groups. Among these 7 miRNAs, except for let-7a, the other 6 miRNAs (miR-1949, miR-125b-5p, miR-296, miR-93, miR-146b, miR-3560) are all first reported for the first time in lung development. Finally, due to the fact that they demonstrated higher fold changes, from these 7 miRNAs we selected miR-125b-5p, miR-296, miR-93, miR-146b and miR-3560 for real-time PCR. We hypothesized that these newly identified miRNAs may play an important role in fetal lung development, and this experimental result could help us to further clarify the mechanism of normal lung development including the development of type II pneumocytes. This may
\end{abstract}

Correspondence to: Dr Xiao-Yu Zhou, Department of Neonates, Nanjing Children's Hospital of Nanjing Medical University, 72 Guangzhou Road, Nanjing 210008, P.R. China

E-mail: xyzhou161@163.com

Key words: lung development, microRNA, SD rats, respiratory distress syndrome, bronchopulmonary dysplasia provide a physiological basis for future research on diseases of lung development.

\section{Introduction}

The discovery of miRNA is considered as one of the major science breakthroughs of the last several years. Different miRNAs are located in several different genomic locations, and because they can regulate the expression of mRNA, they are considered as important regulatory molecules that modulate various biological processes including cellular physiology, developmental timing, cell fate determination, insulin secretion, and progression of various cancers. Certainly, fetal lung development of mammals is also under the control of a complex network of miRNAs. In recent years, a number of miRNA profiling studies evaluating mouse and rat lung development have emerged, Williams et al (1) performed miRNA profiling at 3 time points (P1, P14 and P60) of the developing mouse lung and demonstrated that the overall expression profile of miRNAs was similar for mouse and human tissue. Bhaskaran et al (2) performed miRNA profiling at 7 time points in rat lung development and identified 21 miRNAs that showed significant changes in expression. Carraro et al (3) found that the mir-17 family of miRNA modulates FGF10FGFR2b downstream signaling by specifically targeting STAT3 and MAPK14, hence further modulates epithelial bud morphogenesis of lungs in response to FGF10 signaling.

Though these related studies have reported the role of miRNAs in lung development, it's still necessary to re-screen miRNAs during the process of lung development based on three reasons. First of all, as a result of different research directions, researchers often select different time points of lung development and different screening criteria for miRNAs. Consequently, this will ultimately lead to distinct research significance, even if their research schemes are so similar. In addition, with great innovation of microarray technology and a quick increase of the probe sites, today's microarray contains more than 1891 capture probes, covering all human, mouse and rat miRNAs annotated in miRBase 16.0. Thence theoretically through these improved methods we could identify new miRNAs on lung development not identified before.

Nowadays, in the clinic, a larger number of premature infants are being saved, and as a result respiratory distress syndrome 
(RDS) and bronchopulmonary dysplasia (BPD) have become more and more common. One widely accepted cause of BPD is immature fetal lung development in pregnancy and similarly, one known critical reason of RDS is secretion of insufficient pulmonary surfactant, which also occurs during fetal lung development. Thus, there should be a close link between these two neonatal diseases and the period of lung development. Besides, we have already known that lung development in the rat can be divided into five stages $(4,5)$. In the first 13 days, this phase is the embryonic phase. During this stage lobar division takes place. The second phase is the pseudoglandular phase (13-18 days), in which epithelial tubes of air passages are formed. In the canalicular phase (18-20 days), lumens are divided into many tubules and the interstitium becomes thinner. Furthermore, lamellar bodies begin to emerge. At the saccular phase (20 days to full term), alveolar ducts and air sacs are formed. The final stage occurs after birth and is called the alveolar phase, in which true alveoli are formed. Among these stages, we chose the pseudoglandular, the canalicular and the saccular phases to represent the process of fetal lung development in our experiment.

Although the pathogenesis of the above two diseases has been studied widely before, there are few studies evaluating the links between BPD/RDS and miRNAs expression in fetal lung development. Zhang et al (6) reported that compared to the normal control, in the hyperoxia-exposed BPD group, 14 miRNAs were upregulated, and 7 miRNAs were downregulated. This result further indicates that miRNAs might play an important role in the progress of BPD. Therefore, in light of the above three reasons, we finally chose three key time points [embryonic (E) Day 16 (E16), E19, E21] representing the process of normal fetal lung development to perform a new miRNAs screening, in an attempt to further explore the mechanism of fetal lung development and offer a physiological basis for the research of RDS and BPD in the future.

\section{Materials and methods}

Sprague-Dawley rats. All healthy adult rats (12 female rats and 12 male rats in total) were maintained in a specific-pathogenfree an animal facility at animal center of the Nanjing Medical University. All procedures in this study followed the protocols approved by the Nanjing Medical University Animal Care and Use Committee. Pregnant SD rats were sacrificed with $\mathrm{CO}_{2}$, whole fetal lungs were immediately isolated from rats' fetuses on gestational Days 16, 19 and 21 (E16, E19, and E21), and these three time points were named as group S1(E21), group S2(E19), group S3(E16) respectively. For each group, there were 4 pregnant rats which were selected through a random contrast rule.

After isolation, lungs were washed with PBS. For each group one copy of fetal lungs was randomly kept for histological observation. Total-RNA of the left lungs was isolated using TRIzol (Invitrogen) and the miRNeasy mini kit (Qiagen) according to manufacturer's instructions. RNA quality and quantity was measured using the NanoDrop spectrophotometer (ND-1000, Nanodrop Technologies) and RNA integrity was determined by gel electrophoresis.

Histology. Paraformaldehyde-fixed lung tissue was paraffin embedded and $4 \mu \mathrm{m}$ sections were obtained. Sections were stained with hematoxylin and eosin (H\&E) for morphology detection. H\&E sections were viewed with normal optical microscopy at x40 magnification for observing fetal lung development changes of the 3 groups (S1, S2, S3).

miRNA microarray. After RNA isolation from the fetal lungs, the miRCURY Hy3 $3^{\mathrm{TM}} / \mathrm{Hy} 5^{\mathrm{TM}}$ power labeling kit (Exiqon, Vedbaek, Denmark) was used according to the manufacturer's instractions for miRNA labeling. One microgram of each sample was 3'-end-labeled with $\mathrm{Hy}^{\mathrm{TM}}$ fluorescent label, using T4 RNA ligase by the following procedure. RNA in $2.0 \mu 1$ of water was combined with $1.0 \mu \mathrm{l}$ of CIP buffer and CIP (Exiqon). The mixture was incubated for $30 \mathrm{~min}$ at $37^{\circ} \mathrm{C}$, and was terminated by incubation for $5 \mathrm{~min}$ at $95^{\circ} \mathrm{C}$. Then $3.0 \mu \mathrm{l}$ of labeling buffer, $1.5 \mu \mathrm{l}$ of fluorescent label ( $\left.\mathrm{Hy} 3^{\mathrm{TM}}\right), 2.0 \mu \mathrm{l}$ of DMSO, $2.0 \mu \mathrm{l}$ of labeling enzyme were added into the mixture. The labeling reaction was incubated for $1 \mathrm{~h}$ at $16^{\circ} \mathrm{C}$, and terminated by incubation for $15 \mathrm{~min}$ at $65^{\circ} \mathrm{C}$.

After terminating the labeling procedure, the $\mathrm{Hy} 3^{\mathrm{TM}}$ labeled samples were hybridized on the miRCURY LNA ${ }^{\mathrm{TM}}$ array (v.16.0) (Exiqon) according to the manual. The total $25 \mu \mathrm{l}$ mixture from $\mathrm{Hy}^{\mathrm{TM}}$-labeled samples with of $25 \mu \mathrm{l}$ hybridization buffer were first denatured for $2 \mathrm{~min}$ at $95^{\circ} \mathrm{C}$, incubated on ice for $2 \mathrm{~min}$ and then hybridized to the microarray for $16-20 \mathrm{~h}$ at $56^{\circ} \mathrm{C}$ in a 12 -Bay Hybridization system (Nimblegen Systems, Inc.; Madison, WI, USA), which provides an active mixing action and constant incubation temperature to improve hybridization uniformity and enhance the signal. Following hybridization, the slides were washed several times using wash buffer kit (Exiqon), and finally dried by centrifugation for $5 \mathrm{~min}$ at $400 \mathrm{rpm}$. Then the slides were scanned using the Axon GenePix 4000B microarray scanner (Axon Instruments, Foster City, CA, USA).

Scanned images were then imported into GenePix Pro 6.0 software (Axon) for grid alignment and data extraction. Replicated miRNAs were averaged and miRNAs that had intensities $>50$ in all samples were chosen for calculating the normalization factor. Expressed data were normalized using the median normalization. After normalization, differentially expressed miRNAs were identified through fold-change filtering (fold change>2.0). Hierarchical clustering was performed using the MEV software (v4.6, TIGR).

Quantitative real-time PCR. Total-RNA was isolated from fetal lungs using the TRIzol reagent (Invitrogen Life Technologies). Single-strand cDNA was synthesized as follows: the reverse transcription mixture contained $1 \mu \mathrm{g}$ total-RNA, $0.3 \mu$ l rno-miRNA reverse primer $(1 \mu \mathrm{M})$ (Table I), $0.1 \mu 1 \mathrm{MMLV}$ revertase (200 U/ $\mu 1$, Epicentre), $2 \mu 1$ 10X RT buffer, $2 \mu \mathrm{l}$ dNTP $\operatorname{mix}(2.5 \mathrm{mM}$ each), $0.3 \mu \mathrm{l}$ ribonuclease inhibitor ( $40 \mathrm{U} / \mu 1$, Epicentre), in a $20 \mu 1$ total volume. The reaction was performed at $16^{\circ} \mathrm{C}$ for $30 \mathrm{~min}$ and at $42^{\circ} \mathrm{C}$ for $40 \mathrm{~min}$, followed by heat inactivation at $85^{\circ} \mathrm{C}$ for $5 \mathrm{~min}$. For real-time PCR, $1 \mu \mathrm{l} \mathrm{cDNA}$ was added to $24 \mu \mathrm{l}$ master mix containing $2.5 \mu \mathrm{ldNTP}$ (2.5 mM each), $2.5 \mu \mathrm{l} 10 \mathrm{X}$ PCR buffer (Promega), 1 unit Taq polymerase (Promega), final concentration $0.25 \mathrm{X}$ SYBR-Green I (Invitrogen) and $2 \mu \mathrm{l}$ reverse and forward primers. cDNA was amplified for 35 cycles with the Applied Rotor-Gene 3000 (Corbett Research) real-time PCR system. The primer sequences used are listed 
Table I. Reverse primer sequences.

Gene name

RT primers

U6

rno-miR-93

rno-miR-125b-5p

rno-miR-146b

rno-miR-3560

rno-miR-296
5'-CGCTTCACGAATTTGCGTGTCAT-3'

5'-GTCGTATCCAGTGCGTGTCGTGGAGTCGGCAATTGCACTGGATACGACCTACCTG-3'

5'-GTCGTATCCAGTGCGTGTCGTGGAGTCGGCAATTGCACTGGATACGACTCACAA-3'

5'-GTCGTATCCAGTGCGTGTCGTGGAGTCGGCAATTGCACTGGATACGACACAGCCT-3'

5'-GTCGTATCCAGTGCGTGTCGTGGAGTCGGCAATTGCACTGGATACGACAATGCAC-3' 5'-GTCGTATCCAGTGCGTGTCGTGGAGTCGGCAATTGCACTGGATACGACGGAGAG-3'

Table II. Primers for real-time RT-PCR.

\begin{tabular}{|c|c|c|c|}
\hline \multirow{2}{*}{$\frac{\text { Gene name }}{\text { U6 }}$} & \multicolumn{2}{|r|}{ Primers } & \multirow[t]{2}{*}{$\mathrm{Ta}\left({ }^{\circ} \mathrm{C}\right)$} \\
\hline & $\mathrm{F}$ & 5'-GCTTCGGCAGCACATATACTAAAAT-3' & \\
\hline & $\mathrm{R}$ & 5'-CGCTTCACGAATTTGCGTGTCAT-3' & 60 \\
\hline \multirow[t]{2}{*}{ rno-miR-93 } & GSP & 5'-GGCAAAGTGCTGTTCGTG-3' & \\
\hline & $\mathrm{R}$ & 5'-CAGTGCGTGTCGTGGAGT-3' & 60 \\
\hline \multirow[t]{2}{*}{ rno-miR-125b-5p } & GSP & 5'-GGGTCCCTGAGACCCTAAC-3' & \\
\hline & $\mathrm{R}$ & 5'-CAGTGCGTGTCGTGGAGT-3' & 60 \\
\hline \multirow[t]{2}{*}{ rno-miR-146b } & GSP & 5'-GGGTGAGAACTGAATTCCAT-3' & \\
\hline & $\mathrm{R}$ & 5'-CAGTGCGTGTCGTGGAG-3' & 60 \\
\hline \multirow[t]{2}{*}{ rno-miR-3560 } & GSP & 5'-GTCAAATCCTTGCCCG-3' & \\
\hline & $\mathrm{R}$ & 5'-CAGTGCGTGTCGTGGA-3' & 60 \\
\hline \multirow[t]{2}{*}{ rno-miR-296 } & GSP & 5'-GAGGGTTGGGTGGAGG-3' & \\
\hline & $\mathrm{R}$ & 5'-CAGTGCGTGTCGTGGAG-3' & 60 \\
\hline
\end{tabular}

F, forward; R, reverse; GSP, gene-specific primer.

in Table II. RT and PCR for U6 snRNA were performed in each plate as an endogenous control. The amount of PCR product was calculated from the threshold cycle $(\mathrm{Ct})$, and the comparative $\mathrm{Ct}$ method was used. The relative amount of each miRNA to U6 snRNA was calculated with the equation $2^{-(\mathrm{Ct} \text { microRNA-Ct U6) }}$.

Statistical analysis. Data were analyzed with the SPSS 13.0 statistical package, and the data of the real-time PCR was evaluated by one-way ANOVA. A P-value $<0.05$ was considered significant.

\section{Results}

Histology. In the S3(E16) group some epithelial tubes extending many branches like 'trees' were observed, which were all constructed of tall epithelial cells, arranged in irregular rings (Fig. 1C). In the S2(E19) group the bronchioles started to take shape. The interstitium was thinner than before and some gas chambers and primal alveolars appeared (Fig. 1B). In the S1(E21) group the alveolar structures expanded rapidly and the interstitium became more sparse than in the previous groups (Fig. 1A).
miRNA expression profile. We used the sixth generation of the miRCURY LNA Array (v.16.0) which contains more than 1891 capture probes, covering all human, mouse and rat miRNAs annotated in miRBase 16.0 , as well as all viral miRNAs related to these species. In addition, this array also contains capture probes for 66 new miRPlus ${ }^{\mathrm{TM}}$ human miRNAs. As a result, through this microarray, 167 differentially expressed miRNAs between 3 groups (group S1, S2, S3) passed the foldchange filtering (fold-change $>2.0$ ), including 81 upregulated miRNAs and 86 downregulated miRNAs.

Among these differentially expressed miRNAs, we identified 40 downregulated and 37 upregulated miRNAs in S2/ S3 (fold-change $>2.0$ ); 42 downregulated and 30 upregulated miRNAs in S1/S2 (fold-change $>2.0$ ); 50 downregulated and 48 upregulated miRNAs in S1/S3 (fold-change $>2.0$ ) (Tables V and VI). Then we performed hierarchical clustering to show distinguishable miRNA expression profiling among the groups. In the heat map diagram, each row represents a miRNA and each column represents a group. The miRNA clustering tree is shown on the left, and the group clustering tree appears at the top (Fig. 2).

From all the differentially expressed miRNAs (Tables V and VI) we set a specific criterion for screening miRNAs 

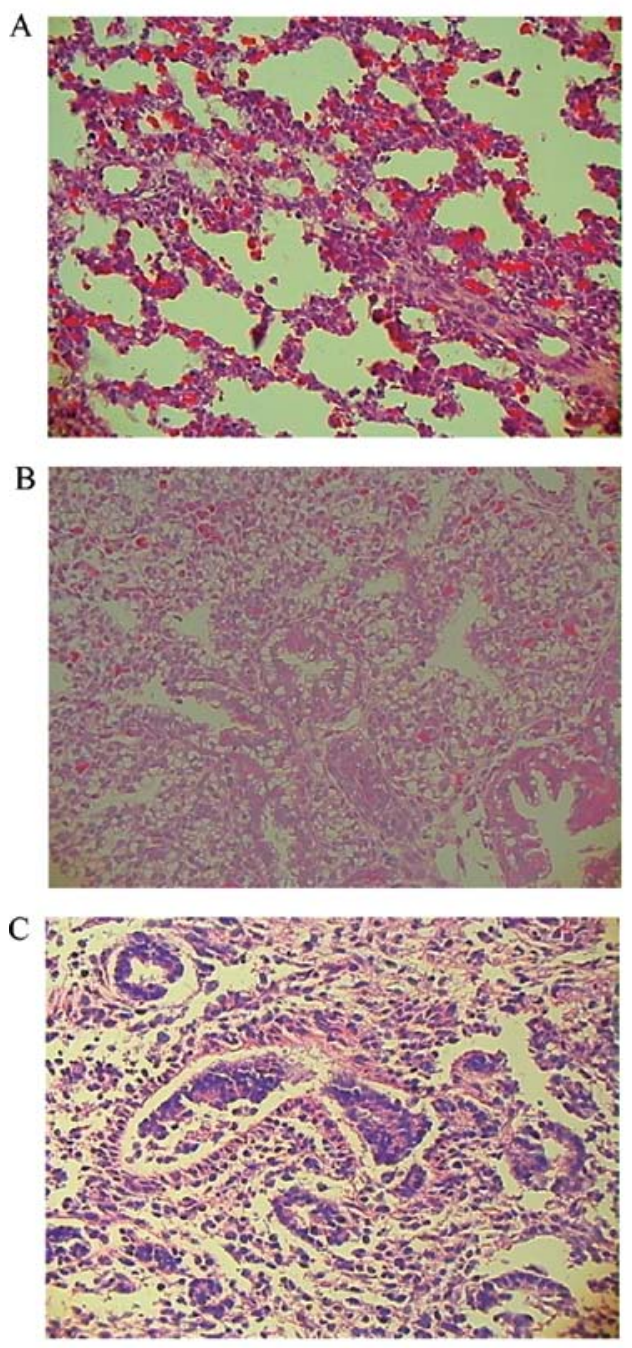

Figure 1. Observation of fetal lung tissue in 3 groups under as optical microscope, H\&E, x40. (A-C) Representative photomicrographs of group S1(E21), S2(E19) and S3(E16), respectively.

we wished to further study. The screening criteria was that the expression of these miRNAs must meet the requirement of fold-changes in $\mathrm{S} 2 / \mathrm{S} 3>2.0$ and $\mathrm{S} 1 / \mathrm{S} 2>2.0$ and $\mathrm{S} 1 / \mathrm{S} 3>4.0$ $[\mathrm{S} 3(\mathrm{E} 16) \rightarrow \mathrm{S} 2(\mathrm{E} 19) \rightarrow \mathrm{S} 1(\mathrm{E} 21)]$. After screening, we found 4 consistently downregulated and 3 consistently upregulated miRNAs that met our requirements between the 3 groups (Tables III and IV). The specific fold-changes of 4 downregulated and 3 upregulated miRNAs are compared using histograms (Fig. 3) based on the data of Tables III and IV. Besides this, the expression patterns of these identified miRNAs are also shown in the line charts (Fig. 4).

Because of showing more obvious fold-changes between 3 groups, at last, we further selected out 5 miRNAs based on the data of Fig. 3, including 3 downregulated miRNAs (miR-125b-5p, miR-296, miR-93) and 2 upregulated miRNAs (miR-146b, miR-3560).

Real-time PCR. These 5 selected miRNAs were confirmed by real-time PCR. We chose these 5 miRNAs for further study based on several reasons as follows. Firstly, among the 4 consistently downregulated miRNAs, miR-125b-5p, miR-296, miR-93 had greater fold-changes between the 3 groups than

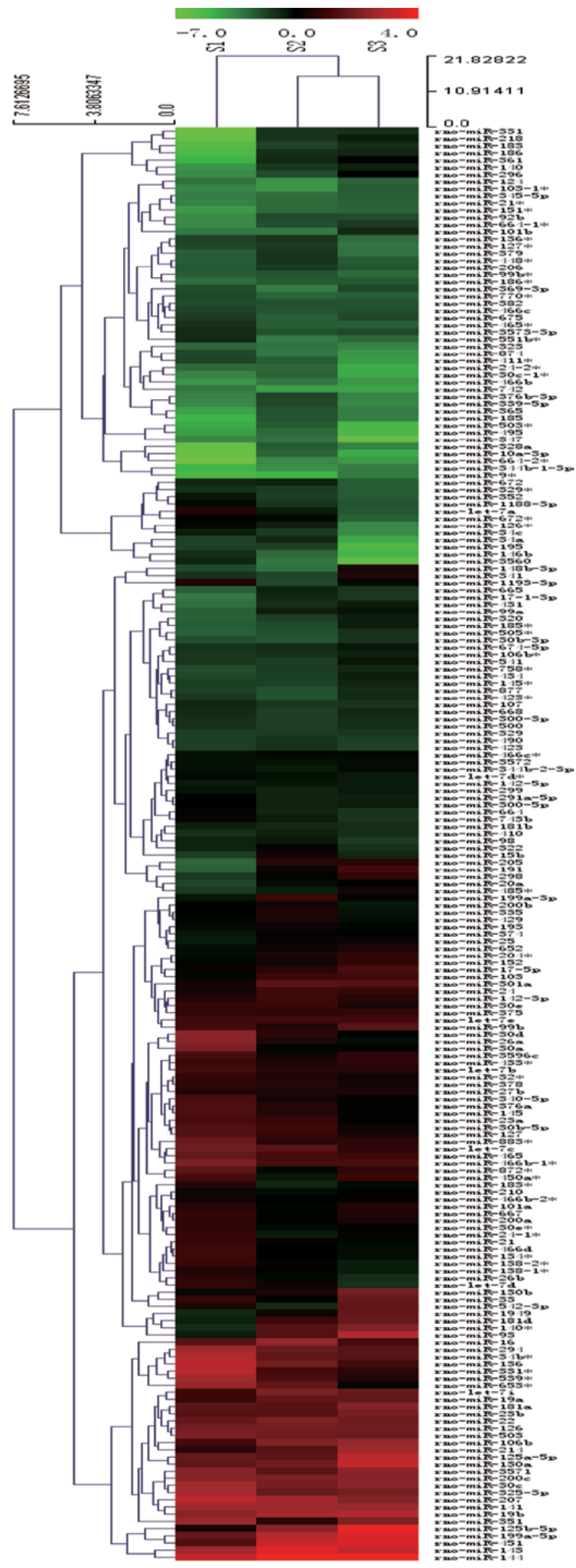

Figure 2. Hierarchical clustering of the 3 groups (S1, S2, S3). Distinguishable miRNA expression profiling is observed. Red indicates high relative expression, green indicates low relative expression and black represents zero. 
Table III. Specific fold-changes of 4 consistently downregulated miRNAs after screening $(\mathrm{S} 3 \rightarrow \mathrm{S} 2 \rightarrow \mathrm{S} 1 \downarrow)$.

\begin{tabular}{lcccc}
\hline & miR-125b-5p & miR-296 & miR-93 & miR-1949 \\
\hline S2/S3 & 0.350006 & 0.248001 & 0.359659 & 0.381056 \\
S1/S2 & 0.273829 & 0.317061 & 0.242748 & 0.42356 \\
S1/S3 & 0.095842 & 0.078631 & 0.087306 & 0.161400
\end{tabular}

Table IV. Specific fold-changes of 3 consistently upregulated miRNAs after screening $(\mathrm{S} 3 \rightarrow \mathrm{S} 2 \rightarrow \mathrm{S} 1 \uparrow$ ).

\begin{tabular}{lccc}
\hline & miR-146b & miR-3560 & let-7a \\
\hline S2/S3 & 5.016317 & 8.421142 & 3.178521 \\
S1/S2 & 3.094662 & 4.888906 & 2.289511 \\
S1/S3 & 15.523805 & 41.170169 & 7.277257 \\
\hline
\end{tabular}

A Fold change of continuous down-regulated miRNAs

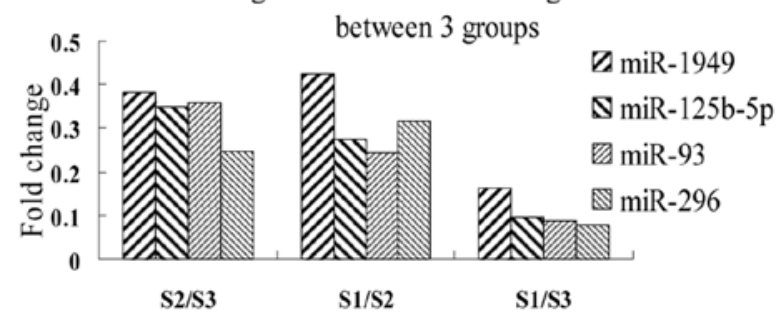

B Fold change of continuous up-regulated miRNAs between 3 groups

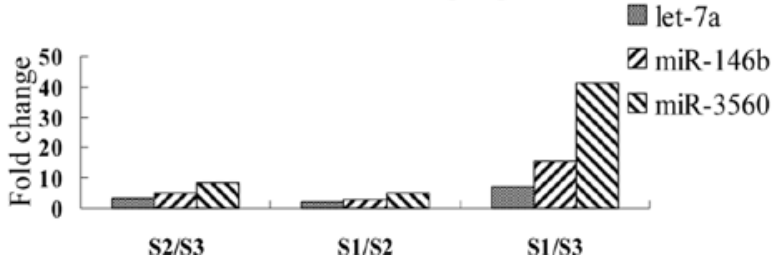

Figure 3. Comparison of specific fold-changes of 7 miRNAs. (A) The specific fold-changes of 4 consistently downregulated miRNAs between the 3 groups and (B) the specific fold-changes of 3 consistently upregulated miRNAs between the 3 groups.

miR-1949. Similarly, among 3 consistently upregulated miRNAs, miR-146b, miR-3560 have greater fold changes between the 3 groups than let-7a (Fig. 3). Secondly, compared to the widely studied let-7a, we have known less about several other miRNAs. So finally we chose miR-125b-5p, miR-296, miR-93, miR-146b, miR-3560 to perform real-time PCR. The relative expressions of these 5 miRNAs are shown in Fig. 5.

\section{Discussion}

In our experiment, we found that miR-1949, miR-125b-5p, miR-296 and miR-93 were consistently downregulated, while miR-146b, miR-3560, let-7a were consistently upregulated between all three groups. Among them, miR-146b, miR-125b-5p, miR-1949 and miR-3560 are reported for the first time in lung development. Specifically for miR-1949 and miR-3560, there were no miRNAs studies involving them
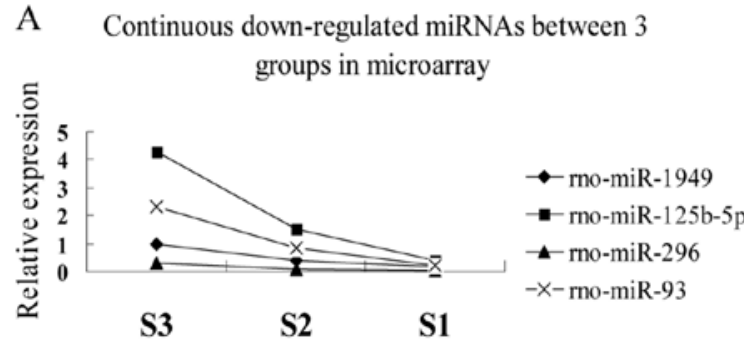

B Continuous up-regulated miRNAs between 3 groups

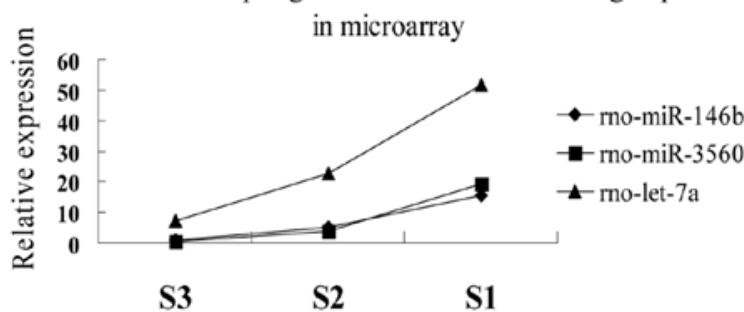

Figure 4. miRNA expression patterns during rat lung development. (A) The relative expression trend of 4 consistently downregulated miRNAs and (B) the relative expression trend of 3 consistently upregulated miRNAs after screening.

before. As for miR-296 and miR-93, they also have rarely been reported in lung development during previous studies.

Before our research, a series of studies had demonstrated the importance of miRNAs in the process of lung physiology. It was reported that miR-146 was upregulated in response to LPS, and negatively regulates the innate immune response (7). Hence the importance of miR-146b was mainly reflected in innate immune and inflammation response $(7,8)$, but in lung development this is the first time it has been reported. Similarly, miR-125b-5p is also mainly related to the immune response (9). It was demonstrated that in response of LPS, miR-125b decreased by inhibition of $\kappa \mathrm{B}-\mathrm{Ras} 2$, an inhibitor of IкB (10). Androulidaki et al (11) further reported that both in vitro and in vivo suppression of miR-125b mainly depended on Akt signaling in murine macrophages. As for miR-93, from the report of Bhaskaran et al (2) miR-93 had a higher expression in E16 and declined with time in SD rat lung tissue. In addi- 
A

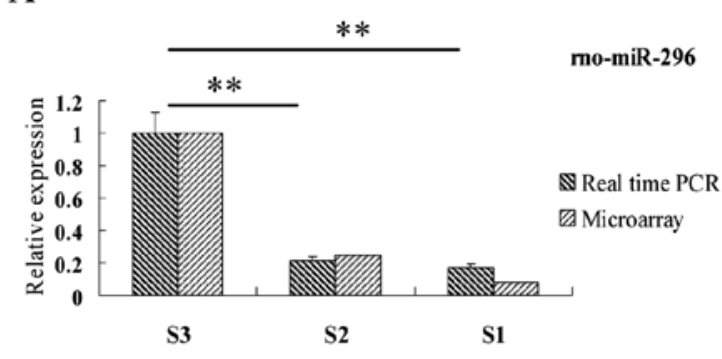

$\mathrm{C}$

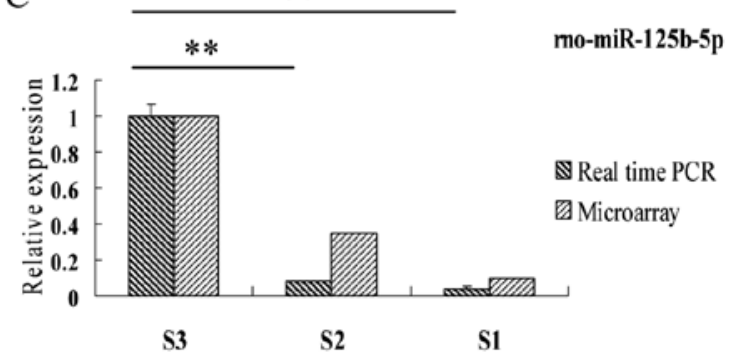

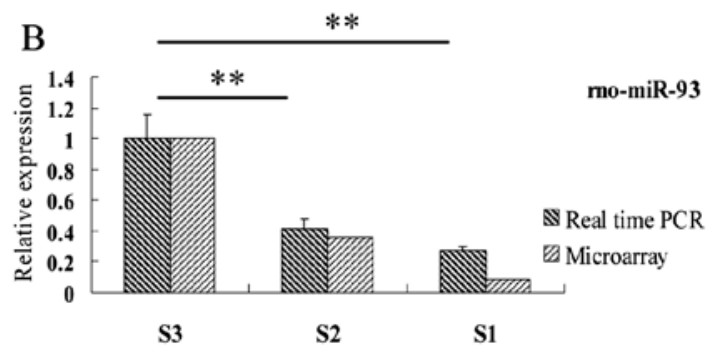

$\mathrm{D}$

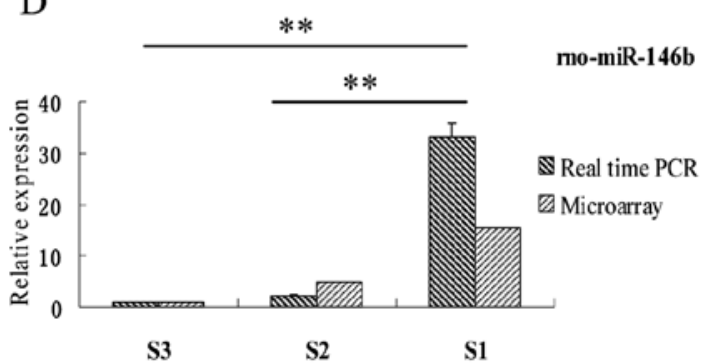

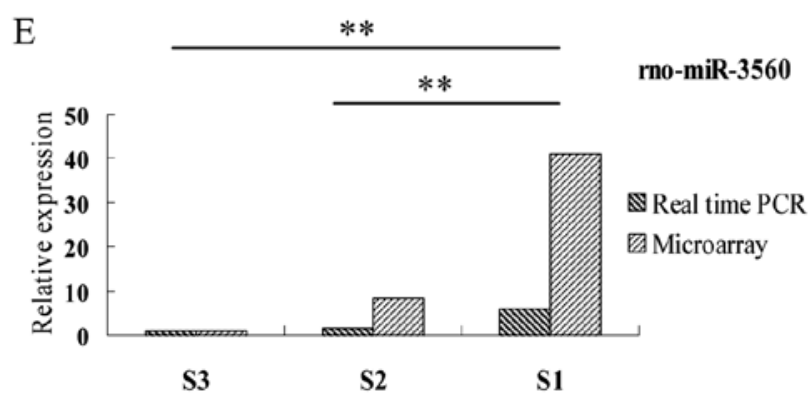

Figure 5. Validation of miRNA microarray results by real-time PCR. Triplicate assays were performed from each RNA sample. Data are normalized using U6 as an endogenous control for RNA input. Fold changes for these miRNAs from array and real-time qRT-PCR are shown as the mean. Error bars represent SE. All exhibited statistical significance of real-time PCR was tested by the one-way ANOVA test $(* * 2<0.001)$

tion, Foshay and Gallicano (12) demonstrated that miR-93 and several other miRNAs are differentially expressed in developing mouse embryos and function to control differentiation of stem cells. Besides, Long et al (13) provided evidence that miR-93 regulates VEGF expression in experimental models of diabetes both in vitro and in vivo. Anti-miR-93 inhibitors increased VEGF release. These findings show that miR-93 plays an important role in early organ development including lung tissue, and maybe it promotes organ development via its role in regulating VEGF expression and differentiation of stem cells. Another mentioned microRNA, miR-296, was found having high expression both in mouse and human fetal lung development (1). Besides, Würdinger et al (14) further demonstrated that miR-296 has a major role in the upregulation of growth factor receptors on endothelial cells during angiogenesis. These facts also show the function of miR-296 in organ growth and development.

Among all those miRNAs on lung development, without no doubt the let-7 family and the miR-17-92 cluster have been studied the most. As for the let-7 family, this is the first reported miRNA family in humans (15). Important known targets of let-7 are the mRNAs for Ras proteins (16). Ras proteins lie downstream of receptor tyrosine kinase signaling, including the fibroblast growth factor (FGF) receptors. FGF signaling is known to be important for lung branching morphogenesis and epithelial cell proliferation (17-19). Hence the let-7 family would be highly expressed and should play an important part in normal neonatal lung development. In addition, Chen et al (20) showed that in the immune response the presence of LPS, let-7i expression is reduced in a MyD88/NF- $\mathrm{KB}$-dependent manner accompanied by a concomitant increase in TLR4 protein. They found that let- $7 \mathrm{~b}$ and let- $7 \mathrm{~g}$ are also predicted to target TLR4 (20). These findings suggest that the let-7 family is essential in the normal immune system of the lungs as well. Beside its roles in these aspects, the let-7 family also plays an important role in the domain of lung cancer because of the ability of modulating proliferation and differentiation. In vitro, Johnson et al (21) showed that let-7 is highly expressed in normal lung tissue, and can repress cell proliferation pathways. Moreover, overexpression of let-7 in cancer cell lines alters cell cycle progression and reduces cell division, providing evidence that let-7 functions as a tumor suppressor in normal lung cells (21). This observation also further supported the links between let-7 and cell proliferation of lungs. In our experiment, we identified several members of the let-7 family as well, such as let-7a, let-7d, let-7c, let-7i (Tables V and VI). In addition, we found that let-7a was consistently upregulated exhibiting more than 2-fold changes between all three groups. From the above 
Table V. Differentially expressed downregulated miRNAs of the 3 groups.

\begin{tabular}{|c|c|c|c|c|c|}
\hline \multicolumn{2}{|c|}{$\mathrm{S} 2$ vs. $\mathrm{S} 3^{\mathrm{a}}$} & \multicolumn{2}{|c|}{$\mathrm{S} 1$ vs. $\mathrm{S} 3^{\mathrm{a}}$} & \multicolumn{2}{|c|}{$\mathrm{S} 1$ vs. S2 ${ }^{\mathrm{a}}$} \\
\hline rno-miR-148b-3p & 0.094091722 & rno-miR-218 & 0.017748926 & rno-miR-331 & 0.025097528 \\
\hline rno-miR-181c* & 0.102332859 & rno-miR-331 & 0.022676474 & rno-miR-218 & 0.029062058 \\
\hline rno-miR-181a-2* & 0.102496854 & rno-miR-361 & 0.035607027 & rno-miR-186 & 0.054194422 \\
\hline rno-miR-708 & 0.158107968 & rno-miR-183 & 0.043789053 & rno-miR-328a & 0.059769138 \\
\hline rno-miR-542-3p & 0.168129140 & rno-miR-186 & 0.044599141 & rno-miR-10a-3p & 0.066155885 \\
\hline rno-miR-345-3p & 0.185715189 & rno-miR-191 & 0.074433158 & rno-miR-183 & 0.067858632 \\
\hline rno-miR-341 & 0.194309188 & rno-miR-296 & 0.078631409 & rno-miR-361 & 0.068270782 \\
\hline rno-miR-872 & 0.198980560 & rno-miR-93 & 0.087306489 & rno-miR-664-2* & 0.087026492 \\
\hline rno-miR-101b & 0.221089511 & rno-miR-125b-5p & 0.095841547 & rno-miR-205 & 0.096042750 \\
\hline rno-miR-675* & 0.222038393 & rno-miR-205 & 0.102436107 & rno-miR-191 & 0.146809908 \\
\hline rno-miR-100 & 0.230750565 & rno-miR-140* & 0.105805164 & rno-miR-185 & 0.157339286 \\
\hline rno-miR-296 & 0.248000552 & rno-miR-140 & 0.107083030 & rno-miR-140* & 0.172848464 \\
\hline rno-miR-221* & 0.269476529 & rno-miR-328a & 0.122790295 & rno-miR-140 & 0.177829281 \\
\hline rno-miR-33 & 0.293467319 & rno-miR-1949 & 0.161399938 & rno-miR-365 & 0.214306279 \\
\hline rno-miR-1193-3p & 0.299534761 & rno-miR-181d & 0.188473763 & rno-miR-503* & 0.216390196 \\
\hline rno-miR-9* & 0.304562081 & rno-miR-148b-3p & 0.189087830 & rno-miR-17-1-3p & 0.216487388 \\
\hline rno-miR-103-1* & 0.318368895 & rno-miR-431 & 0.202831654 & rno-miR-93 & 0.242748162 \\
\hline rno-miR-301b & 0.341714335 & rno-miR-298 & 0.203989814 & rno-miR-146a & 0.249292025 \\
\hline rno-miR-125a-5p & 0.346604792 & rno-miR-101b & 0.209897940 & rno-miR-451 & 0.253399034 \\
\hline rno-miR-125b-5p & 0.350005640 & rno-miR-664- $1^{*}$ & 0.219644982 & rno-miR-15b & 0.257022296 \\
\hline rno-miR-130b & 0.353168958 & rno-miR-451 & 0.222592972 & rno-miR-125b-5p & 0.273828579 \\
\hline rno-miR-324-5p & 0.357412560 & rno-miR-99a & 0.225967175 & rno-miR-99a & 0.287610683 \\
\hline rno-miR-31 & 0.357860445 & rno-miR-9* & 0.239133724 & rno-miR-665 & 0.291447536 \\
\hline rno-miR-93 & 0.359658704 & rno-miR-199a-5p & 0.263862490 & rno-miR-431 & 0.293607410 \\
\hline rno-miR-130a & 0.374817120 & rno-miR-20a & 0.265100100 & rno-miR-181d & 0.304485508 \\
\hline rno-miR-369-3p & 0.378716327 & rno-miR-214 & 0.266488970 & rno-miR-339-5p & 0.312144607 \\
\hline rno-miR-1949 & 0.381055611 & rno-miR-485* & 0.281452769 & rno-miR-92b & 0.314976564 \\
\hline rno-miR-351 & 0.383714084 & rno-miR-341 & 0.282151269 & rno-miR-296 & 0.317061429 \\
\hline rno-miR-185* & 0.385377368 & rno-miR-185* & 0.286100018 & rno-miR-376b-3p & 0.320623917 \\
\hline rno-miR-124 & 0.390480647 & rno-miR-320 & 0.286974485 & rno-miR-298 & 0.327527708 \\
\hline rno-miR-10a-5p & 0.406082775 & rno-miR-130b & 0.297653142 & rno-miR-664-1* & 0.334675953 \\
\hline rno-miR-541 & 0.425408962 & rno-miR-17-1-3p & 0.314625186 & rno-miR-20a & 0.335312329 \\
\hline rno-miR-3568 & 0.431586754 & rno-miR-130a & 0.316640012 & rno-miR-495 & 0.350653084 \\
\hline rno-miR-423* & 0.440840707 & rno-miR-92b & 0.323796325 & rno-miR-199a-3p & 0.381904552 \\
\hline rno-miR-214 & 0.451194456 & rno-miR-344b-1-3p & 0.337673310 & rno-miR-151* & 0.394178815 \\
\hline rno-let-7a- $2^{*}$ & 0.471572424 & rno-miR-185 & 0.340510901 & rno-miR-1949 & 0.423560063 \\
\hline rno-miR-103 & 0.477689243 & rno-miR-151* & 0.351659779 & rno-miR-199a-5p & 0.425979254 \\
\hline rno-miR-125a-3p & 0.485123886 & rno-miR-125a-5p & 0.385950379 & rno-miR-301a & 0.428990949 \\
\hline rno-miR-877 & 0.486867326 & rno-miR-106b & 0.416344581 & rno-let-7i & 0.460781156 \\
\hline rno-miR-485* & 0.498217593 & rno-miR-505* & 0.417283916 & rno-miR-448* & 0.474806300 \\
\hline & & rno-miR-103 & 0.429258011 & rno-miR-379 & 0.476652731 \\
\hline & & rno-miR-434 & 0.437993715 & rno-miR-143 & 0.485784973 \\
\hline & & rno-miR-665 & 0.444955831 & & \\
\hline & & rno-miR-542-3p & 0.450829869 & & \\
\hline & & rno-miR-17-5p & 0.463810796 & & \\
\hline & & rno-miR-103-1* & 0.466393222 & & \\
\hline & & rno-miR-365 & 0.467547660 & & \\
\hline & & rno-miR-301a & 0.468096601 & & \\
\hline & & rno-miR-204* & 0.469731276 & & \\
\hline & & rno-miR-758* & 0.494091963 & & \\
\hline
\end{tabular}

${ }^{a}$ Two-fold downregulated miRNAs (arranged from high to low). 
Table VI. Differentially expressed upregulated miRNAs of the 3 groups.

\begin{tabular}{|c|c|c|c|c|c|}
\hline \multicolumn{2}{|c|}{$\mathrm{S} 2$ vs. S3a } & \multicolumn{2}{|c|}{$\mathrm{S} 1$ vs. S3a } & \multicolumn{2}{|c|}{$\mathrm{S} 1$ vs. S2 ${ }^{\mathrm{a}}$} \\
\hline rno-miR-328b-3p & 55.43029872 & rno-miR-3560 & 41.17016898 & rno-miR-1193-3p & 5.522615564 \\
\hline rno-miR-34b & 25.20420420 & rno-miR-146b & 15.52380467 & rno-miR-3560 & 4.888905952 \\
\hline rno-miR-195 & 13.54962858 & rno-miR-195 & 13.35300725 & rno-miR-551b* & 4.873483536 \\
\hline rno-miR-34a & 12.42613290 & rno-miR-340-3p & 11.43789966 & rno-miR-3596b & 4.612404060 \\
\hline rno-miR-347 & 10.65967283 & rno-miR-126* & 11.37482850 & rno-miR-30a & 4.448185340 \\
\hline rno-miR-3560 & 8.421141536 & rno-miR-34c & 8.819649047 & rno-miR-351 & 3.656196612 \\
\hline rno-miR-126* & 7.523952406 & rno-miR-34a & 7.506207336 & rno-miR-331* & 3.647136410 \\
\hline rno-miR-503* & 7.362280702 & rno-let-7a & 7.277256972 & rno-miR-872* & 3.472207096 \\
\hline rno-miR-495 & 6.028228773 & rno-miR-672* & 6.182533418 & rno-miR-26a & 3.452368618 \\
\hline rno-miR-672* & 5.260179147 & rno-miR-653* & 6.113379807 & rno-miR-450a & 3.284467450 \\
\hline rno-miR-146b & 5.016316626 & rno-miR-26a & 5.940862902 & rno-miR-146b & 3.094662045 \\
\hline rno-miR-34c & 4.506134424 & rno-miR-30d & 5.322979658 & rno-miR-30d & 3.044324090 \\
\hline rno-miR-10a-3p & 4.097022079 & rno-miR-411* & 5.276145472 & rno-miR-183* & 2.938326520 \\
\hline rno-miR-30c- $1^{*}$ & 3.880991088 & rno-miR-331* & 4.862644551 & rno-miR-24-1* & 2.889240932 \\
\hline rno-miR-24-2* & 3.864698405 & rno-miR-874 & 4.551089902 & rno-miR-542-3p & 2.681449923 \\
\hline rno-miR-150 & 3.671263592 & rno-miR-539* & 4.305674923 & rno-miR-539* & 2.621550834 \\
\hline rno-miR-653* & 3.464938036 & rno-let-7d & 4.232003213 & rno-miR-34b* & 2.423233055 \\
\hline rno-miR-411* & 3.317823169 & rno-miR-1188-3p & 4.122995241 & rno-miR-874 & 2.413460795 \\
\hline rno-miR-339-5p & 3.191308237 & rno-miR-352 & 3.863046748 & rno-miR-369-3p & 2.411181539 \\
\hline rno-let-7a & 3.178520626 & rno-miR-136 & 3.779750375 & rno-miR-352 & 2.337056877 \\
\hline rno-miR-379 & 3.124849546 & rno-miR-30a & 3.710021556 & rno-miR-136 & 2.305536320 \\
\hline rno-miR-672 & 3.073862020 & rno-miR-24-2* & 3.669641211 & rno-miR-1188-3p & 2.298812988 \\
\hline rno-miR-376b-3p & 3.065376187 & rno-miR-551b* & 3.447018045 & rno-miR-465* & 2.298723191 \\
\hline rno-let-7d & 2.913643907 & rno-miR-26b & 3.337770797 & rno-let-7a & 2.289510696 \\
\hline rno-miR-136* & 2.806401138 & rno-miR-138-2* & 3.024870130 & rno-miR-883* & 2.217677800 \\
\hline rno-miR-127* & 2.788147050 & rno-miR-743b & 2.893691660 & rno-miR-3573-3p & 2.199396790 \\
\hline rno-miR-322 & 2.718108021 & rno-miR-672 & 2.876126516 & rno-miR-742 & 2.165992682 \\
\hline rno-miR-16 & 2.412443817 & rno-miR-34b* & 2.644856632 & rno-miR-134* & 2.038410918 \\
\hline rno-miR-15b & 2.290078069 & rno-miR-742 & 2.462802491 & rno-miR-124 & 2.030618140 \\
\hline rno-miR-433 & 2.184634072 & rno-miR-465 & 2.401121956 & rno-miR-148b-3p & 2.009611745 \\
\hline rno-miR-365 & 2.181679706 & rno-miR-664 & 2.385839913 & & \\
\hline rno-miR-185 & 2.164182316 & rno-miR-376a & 2.356517858 & & \\
\hline rno-miR-542-5p & 2.159287689 & rno-miR-134* & 2.348356145 & & \\
\hline rno-miR-222 & 2.149338114 & rno-miR-30c- $1^{*}$ & 2.290029357 & & \\
\hline rno-miR-98 & 2.148547043 & rno-miR-127* & 2.276946053 & & \\
\hline rno-miR-328a & 2.054409673 & rno-miR-450a* & 2.272963605 & & \\
\hline rno-miR-448* & 2.052694520 & rno-miR-329* & 2.244228769 & & \\
\hline & & rno-miR-145 & 2.236167326 & & \\
\hline & & rno-miR-294 & 2.190704795 & & \\
\hline & & rno-miR-138-1* & 2.167812378 & & \\
\hline & & rno-miR-30b-5p & 2.162192845 & & \\
\hline & & rno-miR-340-5p & 2.148757049 & & \\
\hline & & rno-miR-23a & 2.147419285 & & \\
\hline & & rno-let-7c & 2.146358153 & & \\
\hline & & rno-miR-136 & 2.071692663 & & \\
\hline & & rno-miR-127 & 2.065187461 & & \\
\hline & & rno-miR-21 & 2.060560052 & & \\
\hline & & rno-miR- $883^{*}$ & 2.053969554 & & \\
\hline
\end{tabular}

${ }^{a}$ Two-fold upregulated miRNAs (arranged from high to low). 
we could see that the let-7 family plays an indispensable role in normal lung development and homeostasis.

Except for the let-7 family just discussed, the expression of the miR-17-92 cluster is also high in embryonic development. Its expression declines steadily through development (22). Ventura et al (23) demonstrated that mice deficient in the miR-17-92 cluster exhibit lung hypoplasia defects characterized by smaller size, hypoplasia of the lung, ventricular septal defects, and by abnormal B-cell development. On the other hand, the overexpression of the miR-17-92 cluster in murine models resulted in an abnormal phenotype manifested by absence of terminal air sacs, which were replaced with highly proliferative, undifferentiated epithelium (22). In our research, we also found some members, such as miR-20a, miR-17-5p, miR-17-1-3p (Tables V and VI), they were downregulated in at least one pair of the 3 groups. However, due to the fact that the expression of the miR-17-92 cluster declines rapidly through the process of lung development, members that were consistently downregulated exhibiting more than 2-fold change between all three groups were not identified.

Apart from the above miRNAs discussed, we also found other ones reported in previous studies on lung development, such as miR-298, miR-146a, miR-199a, miR-127, miR-15b, miR-16, miR-26a (Tables V and VI). Due to space constraints of this manuscript, we will not discuss them. These several miRNAs all showed significant fold changes, but interestingly they did not show fold-changes between all three groups. We hypothesize that the reason is related to our strict screening criteria for microarray, requesting consistent $>2$-fold changes between all three groups.

In the clinic, advancements in neonatal techniques have improved the prognosis of preterm infants, and the followed incidence of BPD and RDS also gradually increases. Though there have not been accurate statistics of a large sample study in China, in America, the incidence of BPD has risen to about 3,000-7,000 birth per year (24). Currently, most researchers believe that BPD is a sophisticated networked disease caused by many factors. Although a new definition for BPD has been developed (25), the essence of this disease has already widely been agreed on, namely that it is a lung injury led by various risk factors including oxygen toxicity, mechanical ventilation, infection and inflammation on the basis of genetic susceptibility $(25,26)$. Besides these factors, it has also been reported both in China and abroad that the incidence of BPD gradually increases with gestational age and birth-weight decreases $(24,27)$. These findings show that the immature development of the fetal lungs is a key of the pathogenesis of BPD. In premature infants, because of lower numbers and a simpler structure of alveolars, the whole process of lung development has not yet been fulfilled. Then in the wake of being affected by different risk factors, it will finally lead to lung injury and a developmental lag.

Besides BPD, RDS is another common disease in newborns. Nowadays, it has already been proven that lack of alveolar surfactant is an important cause of RDS in the process of lung development. Simultaneously, it has been reported that the occurrence of RDS is also closely-related to gestational age and birth-weight during late pregnancy $(28,29)$. We therefore, speculated whether the lungs would develop more completely with increased gestational age and birth-weight. This leads to a lower incidence of RDS along with an increase of secreting alveolar surfactant.

In conclusion, our experiments identified several consistently differentially expressed miRNAs between all three groups in fetal lung development. These results support the notion that to some degree these newly found miRNAs play a role in lung development, and we think it may help us to clarify the mechanism of normal lung development including the development type II pneumocytes, which may further provide a physiological basis for future research on RDS and BPD.

\section{Acknowledgements}

This study was supported by grants from the Project Foundation of Jiangsu Province Health Department (no. H200642). We thank Mrs. Jie Qiu for his assistance with the manuscript.

\section{References}

1. Williams AE, Moschos SA, Perry MM, Barnes PJ and Lindsay MA: Maternally imprinted microRNAs are differentially expressed during mouse and human lung development. Dev Dyn 236: 572-580, 2007.

2. Bhaskaran M, Wang Y, Zhang H, Weng T, Baviskar P, Guo Y, Gou D and Liu L: MicroRNA-127 modulates fetal lung development. Physiol Genomics 37: 268-278, 2009.

3. Carraro G, El-Hashash A, Guidolin D, Tiozzo C, Turcatel G, Young BM, De Langhe SP, Bellusci S, Shi W, Parnigotto PP and Warburton D: miR-17 family of microRNAs controls FGF10mediated embryonic lung epithelial branching morphogenesis through MAPK14 and STAT3 regulation of E-Cadherin distribution. Dev Biol 333: 238-250, 2009.

4. Burri PH: Fetal and postnatal development of the lung. Annu Rev Physiol 46: 617-628, 1984.

5. Zoetis T and Hurtt ME: Species comparison of lung development. Birth Defects Res B Dev Reprod Toxicol 68: 121-124, 2003.

6. Zhang X,Peng W, Zhang S, Wang C,He X,Zhang Z,Zhu L, Wang Y and Feng Z: MicroRNA expression profile in hyperoxia-exposed newborn mice during the development of bronchopulmonary dysplasia. Respir Care 56: 1009-1015, 2011.

7. Taganov KD, Boldin MP, Chang KJ and Baltimore D: NF-kappaBdependent induction of microRNA miR-146, an inhibitor targeted to signaling proteins of innate immune responses. Proc Natl Acad Sci USA 103:12481-12486, 2006.

8. Perry MM, Williams AE, Tsitsiou E, Larner-Svensson HM and Lindsay MA: Divergent intracellular pathways regulate interleukin-1beta-induced miR-146a and miR-146b expression and chemokine release in human alveolar epithelial cells. FEBS Lett 583: 3349-3355, 2009.

9. Tili E, Michaille JJ, Cimino A, Costinean S, Dumitru CD, Adair B, Fabbri M, Alder H, Liu CG, Calin GA and Croce CM: Modulation of miR-155 and miR-125b levels following lipopolysaccharide/TNF-alpha stimulation and their possible roles in regulating the response to endotoxin shock. J Immunol 179: 5082-5089, 2007.

10. Murphy AJ, Guyre PM and Pioli PA: Estradiol suppresses NF-kappaB activation through coordinated regulation of let-7a and miR-125b in primary human macrophages. J Immunol 184: 5029-5037, 2010

11. Androulidaki A, Iliopoulos D, Arranz A, Doxaki C, Schworer S, Zacharioudaki V, Margioris AN, Tsichlis PN and Tsatsanis C: The kinase Akt1 controls macrophage response to lipopolysaccharide by regulating microRNAs. Immunity 31: 220-231, 2009.

12. Foshay KM and Gallicano GI: miR-17 family miRNAs are expressed during early mammalian development and regulate stem cell differentiation. Dev Biol 326: 431-443, 2009.

13. Long J, Wang Y, Wang W, Chang BH and Danesh FR: Identification of microRNA-93 as a novel regulator of vascular endothelial growth factor in hyperglycemic conditions. J Biol Chem 285: 23457-23465, 2010.

14. Würdinger T, Tannous BA, Saydam O, Skog J, Grau S, Soutschek J, Weissleder R, Breakefield XO and Krichevsky AM: miR-296 regulates growth factor receptor overexpression in angiogenic endothelial cells. Cancer Cell 14: 382-393, 2008. 
15. Hutvágner G, McLachlan J, Pasquinelli AE, Bálint E, Tuschl T and Zamore PD: A cellular function for the RNA-interference enzyme Dicer in the maturation of the let-7 small temporal RNA. Science 293: 834-838, 2001.

16. Johnson SM, Grosshans H, Shingara J, Byrom M, Jarvis R, Cheng A, Labourier E, Reinert KL, Brown D and Slack FJ: Ras is regulated by the let-7 microRNA family. Cell 120: 635-647, 2005 .

17. Cardoso WV and Lu J: Regulation of early lung morphogenesis: questions facts and controversies. Development 133: 1611-1624, 2006.

18. White AC, Xu J, Yin Y, Smith C, Schmid G and Ornitz DM: Fgf9 and Shh signaling coordinate lung growth and development through regulation of distinct mesenchymal domains. Development 133: $1507-1517,2006$.

19. Ramasamy SK, Mailleux AA, Gupte VV, Mata F, Sala FG, Veltmaat JM, Del Moral PM, De Langhe S, Parsa S, Kelly LK, Kelly R, Shia W, Keshet E, Minoo P, Warburton D and Bellusci S: Fgf10 dosage is critical for the amplification of epithelial cell progenitors and for the formation of multiple mesenchymal lineages during lung development. Dev Biol 307: 237-247, 2007.

20. Chen XM, Splinter PL, O'Hara SP and LaRusso NF: A cellular micro-RNA, let-7i, regulates Toll-like receptor 4 expression and contributes to cholangiocyte immune responses against Cryptosporidium parvum infection. J Biol Chem 282: 28929-28938, 2007.

21. Johnson CD, Esquela-Kerscher A, Stefani G, Byrom M, Kelnar K, Ovcharenko D, Wilson M, Wang X, Shelton J, Shingara J, Chin L, Brown D and Slack FJ: The let-7 microRNA represses cell proliferation pathways in human cells. Cancer Res 67: 7713-7722, 2007.
22. Lu Y, Thomson JM, Wong HY, Hammond SM and Hogan BL: Transgenic overexpression of the microRNA miR-17-92 cluster promotes proliferation and inhibits differentiation of lung epithelial progenitor cells. Dev Biol 310: 442-453, 2007.

23. Ventura A, Young AG, Winslow MM, Lintault L, Meissner A, Erkeland SJ, Newman J, Bronson RT, Crowley D, Stone JR, Jaenisch R, Sharp PA and Jacks T: Targeted deletion reveals essential and overlapping functions of the miR-17 through 92 family of miRNA clusters. Cell 132: 875-886, 2008.

24. Monte LF, Silva Filho LV, Miyoshi MH and Rozov T: Bronchopulmonary dysplasia. J Pediatr (Rio J) 81: 99-110, 2005 (In Portuguese).

25. Jobe AH and Bancalari E: Bronchopulmonary dysplasia. Am J Respir Crit Care Med 163: 1723-1729, 2001.

26. Coalson JJ: Pathology of new bronchopulmonary dysplasia. Semin Neonatol 8: 73-81, 2003.

27. Yu JQ, Zhang ZM, Zhang XY, Liu J and Feng ZC: An analysis of risk factors of premature infants with bronchopulmonary dysplasia. Chin Woman Child Health Res 3: 261-263, 2010.

28. Dani C, Reali MF, Bertini G, Wiechmann L, Spagnolo A Tangucci M and Rubaltelli FF: Risk factors for the development of respiratory distress syndrome and transient tachypnoea in newborn infants. Eur Respir J 14: 155-159, 1999.

29. Qian LL, Liu CQ, Guo YX, Jiang YJ, Ni LM, Xia SW, Liu XH, Zhuang WZ, Xiao ZH, Wang SN, Zhou XY and Sun B: Current status of neonatal acute respiratory disorders: a one-year prospective survey from a Chinese neonatal network. Chin Med J (Engl) 123: 2769-2775, 2010. 